\title{
Correction to: Sepsis patients with complication of hypoglycemia and hypoalbuminemia are an early and easy identification of high mortality risk
}

\author{
Makoto Furukawa $^{1} \cdot$ Kosaku Kinoshita $^{1}$ (D) . Junko Yamaguchi ${ }^{1} \cdot$ Satoshi Hori $^{1} \cdot$ Atsushi Sakurai $^{1}$
}

Published online: 26 October 2019

(c) The Author(s) 2019

\section{Correction to: Internal and Emergency Medicine (2019) 14:539-548 \\ https://doi.org/10.1007/s11739-019-02034-2}

In the original article, there were errors in Unit of serum albumin level and the Cases numbers in Table 4.

Unit of serum albumin level was published incorrectly as $2.8 \mathrm{mg} / \mathrm{dl}$ throughout the article. The correct unit should read as $2.8 \mathrm{~g} / \mathrm{dl}$.
In Table 4, the numbers appearing in column 2, under "Inter -G+ non- hypo-A" and column 6, "Hypo-A" was published incorrectly as 112 and 147 . The corrected numbers should read as 102 and 156 respectively.

Publisher's Note Springer Nature remains neutral with regard to jurisdictional claims in published maps and institutional affiliations.

The original article can be found online at https://doi.org/10.1007/ s11739-019-02034-2.

Kosaku Kinoshita

kinoshita.kosaku@nihon-u.ac.jp

Makoto Furukawa

Furukawa.makoto@nihon-u.ac.jp

Junko Yamaguchi

yamaguchi.junko@nihon-u.ac.jp

Satoshi Hori

horisa02@yahoo.co.jp

Atsushi Sakurai

sakurai.atsushi@nihon-u.ac.jp

1 Division of Emergency and Critical Care Medicine,

Department of Acute Medicine, Nihon University School

of Medicine, 30-1, Oyaguchi Kami-cho, Itabashi-ku,

Tokyo 173-8610, Japan 